\title{
Non-Fusion Mutations in Endometrial Stromal Sarcomas: What is the Potential Impact on Tumorigenesis through Cell Cycle Dysregulation?
}

Snehal B. Patel, M.D., Ph.D. ${ }^{\mathrm{a}, \mathrm{b}, \mathrm{c}}$, Colin McCormack, M.D. ${ }^{\mathrm{a}}$, Jennelle C. Hodge, Ph.D. ${ }^{\mathrm{a}, \mathrm{d}, \mathrm{e}}$

${ }^{a}$ Department of Pathology and Laboratory Medicine, Cedars-Sinai Medical Center, Los Angeles CA, USA

${ }^{b}$ Molecular Diagnostics Section, Laboratory of Pathology, National Cancer Institute, National Institutes of Health, Bethesda, MD, USA

'Strata Oncology, Ann Arbor, MI, USA

${ }^{\mathrm{d}}$ Department of Pediatrics, University of California Los Angeles, Los Angeles, CA, USA

'Department of Medical and Molecular Genetics, Indiana University School of Medicine, Indianapolis, IN, USA

Corresponding Author:

Jennelle Hodge, Ph.D.

Indiana University School of Medicine

Department of Medical and Molecular Genetics

975 W. Walnut Street, IB-354

Indianapolis, IN 46202

Email: jhodge1@iu.edu

Phone: (317) 274-5749

Fax: (317) 278-1616

Word count: 2023

This is the author's manuscript of the article published in final edited form as:

Patel, S. B., McCormack, C., \& Hodge, J. C. (2020). Non-fusion mutations in endometrial stromal sarcomas: What is the potential impact on tumourigenesis through cell cycle dysregulation? Journal of Clinical Pathology, 73(12), 830-835. https://doi.org/10.1136/jclinpath-2020-206432 


\begin{abstract}
Targeted next generation sequencing using the 50 gene Ion AmpliSeq Cancer Hotspot Panel v2 identified two significant point mutations in endometrial stromal sarcomas. Case 1 is a uterine mass from a quadragenarian female with a karyotype lacking any known ESS rearrangements but demonstrated to have a $C T N N B 1$ activating mutation (c.133T $>\mathrm{C}, \mathrm{p}$.[Ser45Pro]). Analysis of a uterine mass from case 2, a sexagenarian female, revealed bi-allelic CDKN2A inactivating mutations (c.172C $>$ T, p.[Arg58Ter] and a deletion). Break-apart FISH studies to identify YWHAE, JAZF1, and PHF1 rearrangements were negative in both tumors. We propose a model in which these point mutations may affect cell proliferation, converging at Wnt signaling and G1-S checkpoint control, that independently or in concert with a rare gene fusion result in endometrial stromal sarcoma tumor development or progression.
\end{abstract}

Keywords: $\beta$ catenin; $C T N N B 1 ; \mathrm{p} 16 ; C D K N 2 A$; endometrial stromal tumors; endometrial stromal sarcomas 


\section{INTRODUCTION}

Endometrial stromal tumors are rare neoplasms of the female genitourinary tract characterized by recurrent gene fusions involving JAZF1 or PHF1 in low-grade endometrial stromal sarcomas (ESS) and endometrial stromal nodules (ESN) or YWHAE in high-grade ESS. While recurrent gene fusions are diagnostically useful features of these tumors, a significant minority lack such rearrangements ${ }^{1-6}$. The small subset of ESS with no detectable fusions may reflect insufficient testing sensitivity due to low prevalence fusions or variable fusion partners, or may represent a distinct molecular subgroup. It has been suggested that, unlike fusions, small nucleotide variants (SNVs) are not likely drivers of ESS based on finding only a few affected cancer genes with alterations outside of established cancer hotspots. However, this conclusion was derived from whole exome sequencing of only three ESS tumors that were predetermined to harbor fusion genes ${ }^{7}$. Thus, whether SNVs are significant drivers or have other functions in ESS lacking common gene fusions is an area that remains to be addressed.

Through targeted next generation sequencing (NGS) in ESS, we identified one case with a well-established $C T N N B 1$ activating mutation and a second case with bi-allelic $C D K N 2 A$ inactivating mutations. SNVs in CTNNB1 are of interest because nuclear accumulation of its encoded protein catenin $\beta 1$ has been observed in the majority of ESS, although no catenin $\beta 1$ mutations were detected in 25 low-grade $\mathrm{ESS}^{7-9}$ or in 8 undifferentiated uterine/endometrial sarcoma $\operatorname{cases}^{7-9}$. In contrast, a catenin $\beta 1$ p.Ser33Asn mutation was identified in one of ten ESN cases ${ }^{8,9}$, while the catenin $\beta 1$ mutation . Thr41Ala was found in one of eight ESS cases ${ }^{10}$ (http://www.cbioportal.org/genie/index.do, accessed on 1/13/2018). Both of these reported catenin $\beta 1$ alterations are stabilizing, but it is not known whether the associated tumors also harbored fusion genes. Our results raise the possibility that SNVs of CNNTB1 and CDKN2A may play a role in ESS tumorigenesis that could be independent of gene fusions, potentially through perturbation of the cell cycle.

\section{CLINICAL SUMMARY}

Case 1: A quadragenarian female with a history of uterine leiomyomas presented with sharp, intermittent left lower quadrant pain and four months of metromenorrhagia. Office ultrasound was remarkable for a left adnexal mass, and she was referred to the emergency department. CT scan at hospital admission showed bilateral adnexal masses concerning for malignancy and peritoneal carcinomatosis. She subsequently underwent dilatation and curettage, with intraoperative frozen section demonstrating a spindle cell lesion resulting in conversion to a diagnostic laparotomy. Multiple peritoneal nodules were appreciated. Frozen section of an omental mass was consistent with ESS, and a total abdominal hysterectomy with bilateral salpingo-oophorectomy was performed.

Case 2: A sexagenarian female with a history of uterine leiomyomas presented with 6 months of progressive right lower quadrant pain and unintended weight loss. Office ultrasound demonstrated significant increase in the size of her fibroids compared to the previous year. Pelvic exam was remarkable for an enlarged and immobile nodular uterus and a palpable nodular anterior vaginal mass of approximately $10 \mathrm{~cm}$ in greatest dimension. MRI was concerning for a sarcoma, and CT showed bilateral pulmonary nodules, hepatic mass, lytic bone lesions, and peritoneal carcinomatosis. She subsequently underwent a radical hysterectomy with bilateral salpingo-oophorectomy. Intraoperative findings included a $16 \mathrm{~cm}$ nodular uterus, peritoneal nodules, dense adhesions, and multiple enlarged pelvic lymph nodes. 
Both patients were discharged after uneventful recovery. Follow-up is not available as their care was transferred to an outside hospital.

\section{MATERIALS AND METHODS}

Approval with waiver of consent was obtained from the Cedars-Sinai Medical Center institutional review board.

\section{Histologic and immunohistochemical staining}

Surgical pathology reports and hematoxylin and eosin (H\&E) and immunohistochemical stained slides were reviewed. Immunohistochemical studies performed on one or both cases included antibodies against catenin $\beta 1$ (14; Cell Marque, 1:25), CD10 (56C6; Leica Biosystems, 1:100), KIT (Rabbit Polyclonal; Dako, 1:100), estrogen receptor (SP-1; Ventana, 1:100), progesterone receptor (IE2; Ventana, 1:100), cyclin D1 (SP-4; Cell Marque, 1:100), actin (Alpha AM-1; Leica Biosystems, 1:200), keratin (AE1/AE3; Leica Biosystems, 1:100), myogenin (MYO18; Leica Biosystems, 1:100), S100 (16/F5; Leica Biosystems, 1:200), and desmin (DE-R11; Leica Biosystems, 1:200).

\section{Genetic analysis}

For NGS, H\&E slides were reviewed to outline the target region and estimate tumor purity. Genomic DNA extraction, sequencing, and variant analysis was performed as previously described $^{11}$. In brief, DNA was extracted from unstained tissue sections with the QIAcube (Qiagen, Germany). The libraries were prepared with the 50 gene AmpliSeq Cancer Hotspot Panel v2 and run on the Ion Torrent Personal Genome Machine (Thermo Fisher Scientific). All high-confidence pathogenic variants were confirmed by bi-directional standard Sanger sequencing.

Chromosome G-banded analysis for Case 1 was completed according to standard methods. Break-apart FISH studies for both Case 1 and Case 2 using YWAHAE, PHF1, and $J A Z F 1$ rearrangements were performed as previously described ${ }^{12}$.

\section{RESULTS \\ Histopathologic and immunohistochemical findings}

The specimen for Case 1 included an enlarged uterus with a $6.5 \mathrm{~cm}$ mass situated at the corpus and invading into the myometrium. H\&E stained sections showed a cellular neoplasm composed of spindled cells arranged in fascicles and prominent spiral arterioles (Fig. 1A). Spindled cells were reminiscent of endometrial stromal cells and had scant to modest eosinophilic cytoplasm and elongated nuclei with fine uniform chromatin (Fig. 1B). Areas of myxoid stroma were noted throughout the tumor (Fig. 1C). There were $>60 \mathrm{mf} / 10 \mathrm{HPF}$ and areas suspicious for angiolymphatic invasion. Involvement of the omentum, urinary bladder, pelvic wall, and large and small bowel was histologically confirmed. Tumor cells were negative for CD10, estrogen receptor, progesterone receptor, actin, desmin, myogenin, keratin AE1/AE3, and S100, and positive for KIT (diffuse) and cyclin D1 (strong/diffuse; Fig. 1D). Catenin $\beta 1$ showed strong and diffuse nuclear and cytoplasmic staining (Fig. 1E). The patient was diagnosed with high grade ESS, although epithelioid cells were not present, and staged as pT4NxM1 (Table 1). 


\begin{tabular}{|c|c|c|c|c|c|c|c|c|c|c|c|c|c|c|}
\hline \multirow[b]{2}{*}{ Age } & \multicolumn{3}{|c|}{ Clinical/Histologic } & \multicolumn{3}{|c|}{ Immunohistochemistry } & \multicolumn{4}{|c|}{ Sequencing } & \multicolumn{4}{|c|}{ Cytogenetics } \\
\hline & $\begin{array}{c}\text { Grad } \\
\text { e }\end{array}$ & $\begin{array}{l}\mathrm{MF} / \\
\mathrm{HPF}\end{array}$ & $\begin{array}{l}\text { Patholo } \\
\text { gic } \\
\text { Stage }\end{array}$ & $\begin{array}{c}\mathrm{CD} 1 \\
0\end{array}$ & $\begin{array}{c}\text { Catenin } \\
\beta 1\end{array}$ & $\begin{array}{l}\text { Cycli } \\
\text { n D1 }\end{array}$ & Gene & $\begin{array}{l}\text { cDNA } \\
\text { change }\end{array}$ & $\begin{array}{l}\text { Protein } \\
\text { change }\end{array}$ & $\begin{array}{c}\text { VA } \\
\text { F } \\
(\%)\end{array}$ & $\begin{array}{c}Y W H A E \\
\text { FISH }\end{array}$ & $\begin{array}{c}\text { PHF } \\
1 \\
\text { FISH }\end{array}$ & $\begin{array}{c}\text { JAZF } \\
1 \\
\text { FISH }\end{array}$ & Karyotype \\
\hline \multicolumn{15}{|c|}{ Case 1} \\
\hline 40’s & High & $60 / 10$ & $\begin{array}{l}\text { T4NxM } \\
1\end{array}$ & - & $\mathrm{N} / \mathrm{C}$ & + & $\begin{array}{c}\text { CTNNB } \\
1\end{array}$ & $\begin{array}{c}133 \mathrm{~T}> \\
\mathrm{C}\end{array}$ & Ser45Pro & 43 & - & - & - & $\begin{array}{c}48, \mathrm{XX},+1,+1, \mathrm{i}(1)(\mathrm{q} 10) \times 2[ \\
11] / 46, \mathrm{XX}[5]\end{array}$ \\
\hline \multicolumn{15}{|c|}{ Case 2} \\
\hline 60’s & High & $50 / 5$ & $\begin{array}{l}\text { T4N1M } \\
\quad 1\end{array}$ & + & $\mathrm{N} / \mathrm{C}$ & + & $\begin{array}{c}\mathrm{CDKN} 2 \\
\mathrm{~A}\end{array}$ & $\begin{array}{c}172 \mathrm{C}> \\
\mathrm{T}\end{array}$ & $\underset{r}{\operatorname{Arg} 58 \mathrm{Te}}$ & 79 & - & - & - & Not assessed \\
\hline
\end{tabular}


The specimen for Case 2 included a $16 \mathrm{~cm}$ nodular uterus with a $10.5 \mathrm{~cm}$ mass centered at the uterine corpus and invading the lower uterine segment, myometrium, and serosa. H\&E stained sections showed highly cellular proliferation of spindled cells arranged in fascicular and whorled configuration and expanses of myxoid stroma (Fig. 1F). Spiral arterioles with perivascular cuffing were prominent. Cells exhibited scant eosinophilic cytoplasm and elongated hyperchromatic nuclei. Nuclear atypia and mitotic figures were seen at high power (Fig. 1G). There were $>50 \mathrm{mf} / 5 \mathrm{HPF}$ and angiolymphatic invasion was extensive. Epithelioid/rhabdoid cytologic features were noted focally in the primary and metastatic tumor (Fig. 1H). Tumor cells were negative for desmin, estrogen receptor, progesterone receptor, actin, keratin AE1/AE3, and KIT and positive for CD10 (strong/diffuse) and cyclin D1 (moderate to strong/diffuse; Fig. 1I). Catenin $\beta 1$ showed strong and diffuse nuclear and cytoplasmic staining (Fig. 1J). Involvement of the small and large bowel, urinary bladder, one ovary, and multiple lymph nodes was histologically confirmed. The patient was diagnosed with high grade ESS and staged as pT4N1M1 (Table 1).

\section{Molecular and cytogenetic findings}

In both cases, the tumor cellularity in the macrodissected region used for sequencing was estimated at $85 \%$. In Case 1 , a CTNNBI (catenin $\beta 1$ or $\beta$ catenin) c. $133 \mathrm{~T}>\mathrm{C}$ (p.[Ser45Pro]) mutation was detected at a variant allele frequency of $43 \%$, suggestive of a clonal heterozygous mutation (Table 1). In Case 2, a CDKN2A (cyclin dependent kinase inhibitor 2A or p16/INK4a) c. $172 \mathrm{C}>\mathrm{T}$ (p.[Arg58Ter]) mutation was identified at a variant allele frequency of $79 \%$, indicating a concurrent deletion of the wildtype allele (Table 1). Both are known hotspot mutations (Supplemental Table 1) and were confirmed by Sanger sequencing (Fig. 2A and 2B). Break-apart FISH for YWHAE, PHF1, and JAZF1 loci showed two fused red and green signals within normal limits, indicating an absence of rearrangements involving these genes in both tumors (Fig. 3A-F). Consistently, Case 1 had the karyotype $48, \mathrm{XX},+1,+1, \mathrm{i}(1)(\mathrm{q} 10) \times 2[11] / 46, \mathrm{XX}[5]$ with no evident translocations suggestive of $Y W H A E$, $P H F 1$, or $J A Z F 1$ rearrangement (Fig. 3G).

The characterization of both tumors as high-grade ESS is based on integrating the above morphologic and genetic findings with the current WHO classification scheme ${ }^{13}$, which is further described (See Supplemental Text).

\section{DISCUSSION}

The majority of ESS are characterized by recurrent gene fusions ${ }^{6}$. Neither of the ESS presented here had detectable fusions involving the most commonly involved genes by FISH. While the karyotype in Case 1 was not suggestive of those or other low prevalence fusions, rearrangements can be cytogenetically cryptic. This tumor did have an isochromosome 1q, which appears to be a recurrent but non-specific alteration in $\mathrm{ESS}^{6}$. Rather than a common gene fusion, these tumors had hotspot mutations in established cancer genes, CTNNB1 or CDKN2A. Activating catenin $\beta 1$ mutations are usually primary oncogene drivers (i.e., mutually exclusive of other oncogene alterations) across various tumors, such as colorectal cancer ${ }^{14}$ and hepatoblastomas ${ }^{15}$. In contrast, mutations in $C D K N 2 A$ typically occur alongside primary oncogene drivers, like for other tumor suppressors. Thus, Case 2 may have an oncogene driver that was not detected by our analysis, whereas for Case 1 the catenin $\beta 1$ mutation more likely represents a primary driver. 
The activating mutation in Case 1 , catenin $\beta 1$ p.[Ser45Pro], is associated with nuclear and/or cytoplasmic catenin $\beta 1$ accumulation ${ }^{15-19}$. In Case 2 , the mutation in $C D K N 2 A$, encoding $\mathrm{p} 16 / \mathrm{INK} 4 \mathrm{a}$, results in the truncation of the protein and has experimentally been characterized as a loss-of-function alteration ${ }^{20}$. CDKN2A mutations have not been detected in the 14 ESS cases analyzed $^{7,10,21}$.

Mutations in $C T N N B 1$ or $C D K N 2 A$ may promote ESS tumorigenesis by affecting a common cell cycle regulatory pathway. In the physiologic resting state, catenin $\beta 1$ is primarily present at the plasma membrane and any free protein is phosphorylated and rapidly degraded (Fig. 4A). Normally, in the presence of Wnt signals, catenin $\beta 1$ phosphorylation is inhibited resulting in the accumulation and nuclear import of catenin $\beta 1$ (Fig. 4B). In the nucleus, catenin $\beta 1$ then dimerizes with T cell factor (TCF) and activates/represses Wnt target genes, some of which participate in cell cycle regulation ${ }^{22}$. The expression of one such gene, cyclin D1 $(C C N D 1)$, encoding an allosteric regulator of CDK4 required for passage through the G1-S checkpoint, is frequently upregulated in ESS. Mutations in catenin $\beta 1$ can also result in catenin $\beta 1$ stabilization (Fig. 4C), as was exemplified by the CNNTB1 mutation in Case 1 with associated catenin $\beta 1$ nuclear accumulation and cyclin D1 overexpression.

Cell cycle dysregulation may also be promoted through loss-of-function mutations in p16/INK4, an inhibitor of cyclin D/CDK4 by TCF/ $\beta$-catenin ${ }^{23}$ (Fig. 4D). Indeed, stabilizing mutations of $\beta$-catenin in melanocytes resulting in the downregulation of p16 expression bypassed the requirement for $C D K N 2 A$ mutations in melanoma mouse models ${ }^{23}$. In human melanomas, $C D K N 2 A$ and $C T N N B 1$ mutations are largely mutually exclusive, suggesting that either pathway may contribute to tumorigenesis and/or tumor progression ${ }^{24}$ (TCGA, Provisional dataset, http://www.cbioportal.org/, accessed on 6/10/17).

While $C D K N 2 A$ and $C T N N B 1$ mutations could represent primary drivers in ESS tumorigenesis, other possibilities need to be considered. First, because our analysis does not exclude very rare known alterations in $\operatorname{ESS}$ (e.g., BCOR fusion to $Z C 3 H 7 B$ or internal tandem duplication and MBTD1/CXorf67 fusion) ${ }^{25,26}$ or currently undiscovered fusions, it is possible that $C D K N 2 A$ and $C T N N B 1$ mutations may only cooperate with an undetected fusion driver for malignant transformation. Similar to ESS, CTNNB1 mutations are present in a small but significant minority of another tumor type driven by recurrent fusions, synovial sarcomas; catenin $\beta 1$ accumulates in many of these tumors even in the absence of discernible CTNNB1 mutations ${ }^{27}$. In addition, blockade of Wnt signaling prevents SSX/SS18-fusion positive tumor development in animals ${ }^{27}$. Similarly, the defining translocation of follicular lymphoma, $t(14 ; 18)$, is prevalent in the healthy population, indicating that it is necessary but not sufficient for lymphomagenesis and that cooperation with other genetic or epigenetic alterations may be required $^{28}$. Second, $C D K N 2 A$ and $C T N N B 1$ mutations may be secondary events important for tumor survival and/or progression. Using synovial sarcoma again as a comparator, it has been reported that blockage of Wnt signaling inhibits growth of human synovial sarcoma cell lines ${ }^{27}$. Finally, it is possible the detected mutations have no biological effect, although their known oncogenic role in other tumor types makes this an unlikely possibility. 
In summary, we present two cases of ESS that lack common gene fusions and instead have hotspot point mutations in known cancer genes (CTNNB1 and CDKN2A). Given the frequent nuclear accumulation of catenin $\beta 1$, cyclin D1 upregulation, and p16 downregulation, these mutations could potentially represent mutually exclusive alternative initiating or cancer progression events in a small subset of ESS that either lack fusions or have rare fusions ${ }^{8,29,30}$. The $C T N N B 1$ and $C D K N 2 A$ mutations may act through a common pathway involving cell cycle dysregulation. We emphasize that much remains to be learned about these rare tumors and further examination of those lacking the common fusion genes is necessary to elucidate the full spectrum of potential significant events.

\section{FUNDING}

This research did not receive any specific grant from funding agencies in the public, commercial, or not-for-profit sectors.

\section{COMPETING INTEREST}

None declared 


\section{REFERENCES}

1. Ali RH, Rouzbahman M. Endometrial stromal tumours revisited: an update based on the 2014 WHO classification. Journal of clinical pathology. 2015;68(5):325-332.

2. Hrzenjak A. JAZF1/SUZ12 gene fusion in endometrial stromal sarcomas. Orphanet journal of rare diseases. 2016;11:15.

3. Conklin CM, Longacre TA. Endometrial stromal tumors: the new WHO classification. Advances in anatomic pathology. 2014;21(6):383-393.

4. Lee $\mathrm{CH}$, Nucci MR. Endometrial stromal sarcoma--the new genetic paradigm. Histopathology. 2015;67(1):1-19.

5. Horng HC, Wen KC, Wang PH, Chen YJ, Yen MS, Ng HT. Uterine sarcoma Part II-Uterine endometrial stromal sarcoma: The TAG systematic review. Taiwanese journal of obstetrics \& gynecology. 2016;55(4):472-479.

6. Micci F, Gorunova L, Agostini A, et al. Cytogenetic and molecular profile of endometrial stromal sarcoma. Genes, chromosomes \& cancer. 2016;55(11):834-846.

7. Choi YJ, Jung SH, Kim MS, et al. Genomic landscape of endometrial stromal sarcoma of uterus. Oncotarget. 2015;6(32):33319-33328.

8. Jung $\mathrm{CK}$, Jung JH, Lee $\mathrm{A}$, et al. Diagnostic use of nuclear beta-catenin expression for the assessment of endometrial stromal tumors. Modern pathology : an official journal of the United States and Canadian Academy of Pathology, Inc. 2008;21(6):756-763.

9. Kurihara $S, O d a Y$, Ohishi $Y$, et al. Coincident expression of beta-catenin and cyclin D1 in endometrial stromal tumors and related high-grade sarcomas. Modern pathology : an official journal of the United States and Canadian Academy of Pathology, Inc. 2010;23(2):225-234.

10. AACR Project GENIE: Powering Precision Medicine through an International Consortium. Cancer discovery. 2017;7(8):818-831.

11. Patel SB, Kadi W, Walts AE, et al. Next Generation Sequencing A Novel Approach to Distinguish Multifocal Primary Lung Adenocarcinomas from Intrapulmonary Metastases. The Journal of molecular diagnostics: JMD. 2017.

12. Hodge JC, Bedroske PP, Pearce KE, Sukov WR. Molecular Cytogenetic Analysis of JAZF1, PHF1, and YWHAE in Endometrial Stromal Tumors: Discovery of Genetic Complexity by Fluorescence in Situ Hybridization. The Journal of molecular diagnostics : JMD. 2016;18(4):516-526.

13. Kurman RJ CM, Herrington CS, Young RH, eds. WHO Classification of Tumours of Female Reproductive Organs, World Health Organization Classification of Tumours. Vol 6. Lyon, France: IARC Press; 2014.

14. Sparks AB, Morin PJ, Vogelstein B, Kinzler KW. Mutational analysis of the APC/beta-catenin/Tcf pathway in colorectal cancer. Cancer research. 1998;58(6):1130-1134.

15. Huang $\mathrm{H}$, Fujii $\mathrm{H}$, Sankila $\mathrm{A}$, et al. Beta-catenin mutations are frequent in human hepatocellular carcinomas associated with hepatitis $\mathrm{C}$ virus infection. The American journal of pathology. 1999;155(6):1795-1801.

16. Garcia-Rostan G, Tallini G, Herrero A, D'Aquila TG, Carcangiu ML, Rimm DL. Frequent mutation and nuclear localization of beta-catenin in anaplastic thyroid carcinoma. Cancer research. 1999;59(8):1811-1815.

17. Miyaki M, lijima T, Kimura J, et al. Frequent mutation of beta-catenin and APC genes in primary colorectal tumors from patients with hereditary nonpolyposis colorectal cancer. Cancer research. 1999;59(18):4506-4509.

18. Rimm DL, Caca K, Hu G, Harrison FB, Fearon ER. Frequent nuclear/cytoplasmic localization of beta-catenin without exon 3 mutations in malignant melanoma. The American journal of pathology. 1999;154(2):325-329. 
19. Bonnet S, Gaujoux S, Launay $\mathrm{P}$, et al. Wnt/beta-catenin pathway activation in adrenocortical adenomas is frequently due to somatic CTNNB1-activating mutations, which are associated with larger and nonsecreting tumors: a study in cortisol-secreting and -nonsecreting tumors. The Journal of clinical endocrinology and metabolism. 2011;96(2):E419-426.

20. Parry D, Peters G. Temperature-sensitive mutants of p16CDKN2 associated with familial melanoma. Molecular and cellular biology. 1996;16(7):3844-3852.

21. Murray S, Linardou $\mathrm{H}$, Mountzios $\mathrm{G}$, et al. Low frequency of somatic mutations in uterine sarcomas: a molecular analysis and review of the literature. Mutation research. 2010;686(12):68-73.

22. Kimelman $\mathrm{D}, \mathrm{Xu} \mathrm{W}$. beta-catenin destruction complex: insights and questions from a structural perspective. Oncogene. 2006;25(57):7482-7491.

23. Delmas V, Beermann F, Martinozzi S, et al. Beta-catenin induces immortalization of melanocytes by suppressing p16INK4a expression and cooperates with N-Ras in melanoma development. Genes \& development. 2007;21(22):2923-2935.

24. Cerami E, Gao J, Dogrusoz U, et al. The cBio cancer genomics portal: an open platform for exploring multidimensional cancer genomics data. Cancer discovery. 2012;2(5):401-404.

25. Momeni-Boroujeni A, Chiang S. Uterine mesenchymal tumours: recent advances. Histopathology. 2020;76(1):64-75.

26. Dewaele B, Przybyl J, Quattrone A, et al. Identification of a novel, recurrent MBTD1-CXorf67 fusion in low-grade endometrial stromal sarcoma. Int J Cancer. 2014;134(5):1112-1122.

27. Nielsen TO, Poulin NM, Ladanyi M. Synovial sarcoma: recent discoveries as a roadmap to new avenues for therapy. Cancer discovery. 2015;5(2):124-134.

28. Janz S, Potter M, Rabkin CS. Lymphoma- and leukemia-associated chromosomal translocations in healthy individuals. Genes, chromosomes \& cancer. 2003;36(3):211-223.

29. Iwasaki S, Sudo T, Miwa M, et al. Endometrial stromal sarcoma: clinicopathological and immunophenotypic study of 16 cases. Archives of gynecology and obstetrics. 2013;288(2):385391.

30. Chang B, Lu LX, Tu XY, Cheng YF, Bi R, Yang WT. [Endometrial stromal sarcoma: morphologic features and detection of JAZF1-SUZ12 and YWHAE FAM22 fusion genes]. Zhonghua bing li xue za $z h i=$ Chinese journal of pathology. 2016;45(5):308-313. 

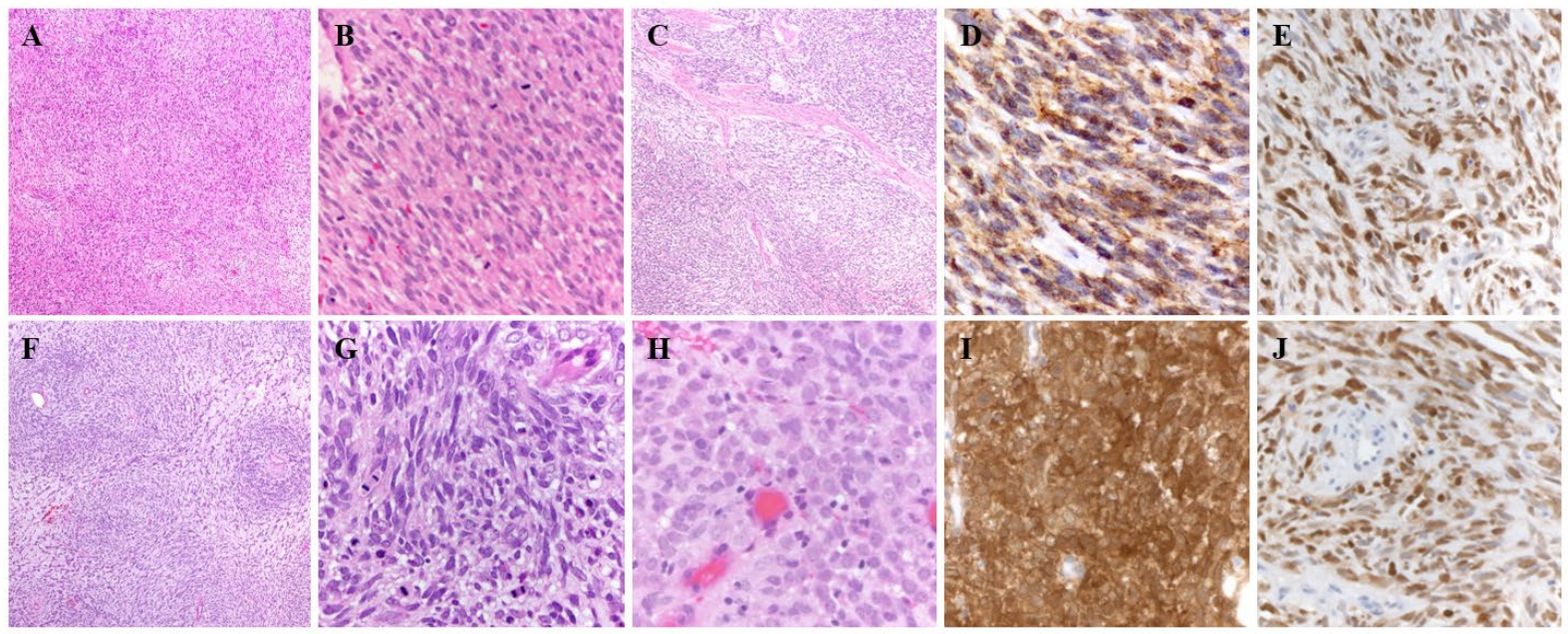

Fig 1. The tumor in Case 1 (top panel) showed spindled cells in fascicular configuration (A) and numerous mitotic figures (B). Expanses of myxoid change were present $(\mathrm{C})$. The tumor in Case 2 (bottom panel) shows a densely cellular spindle cell neoplasm in fascicular and whorled configuration and areas of myxoid change $(F)$. Nuclear atypia and mitotic figures are seen at high power $(\mathrm{G})$. Epithelioid/rhabdoid features were seen focally $(\mathrm{H})$. Both tumors showed strong nuclear and cytoplasmic $\beta$-catenin (D, I) and nuclear cyclin D1/BCL1 (E, J) immunoreactivity throughout the tumor. 

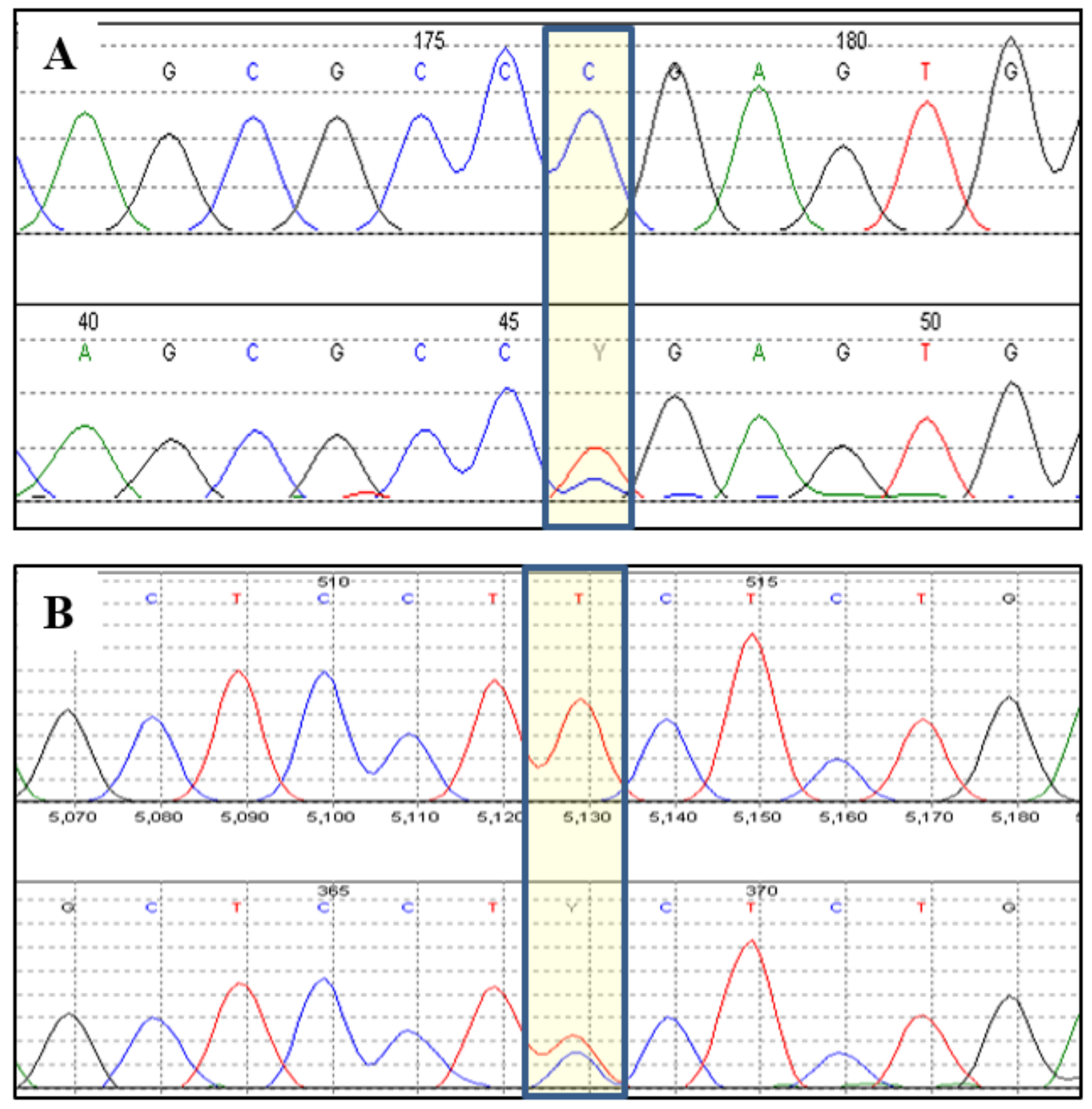

Fig 2. Genetic features of endometrial stromal sarcomas. Sanger sequencing confirmed the molecular alterations (A) $C T N N B 1$ c.133T $>\mathrm{C}$ and (B) $C D K N 2 A$ c.172C $>\mathrm{T}$ discovered by next generation sequencing in the tumors in Case 1 and 2, respectively. Each electropherogram displays the reference sequence on top and the patient tumor sample sequence on the bottom. 

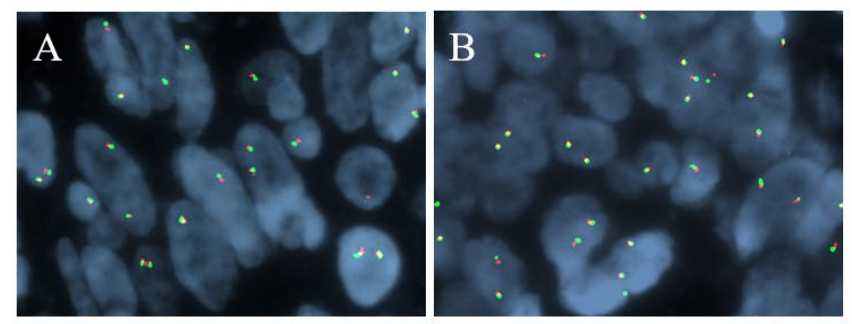

G
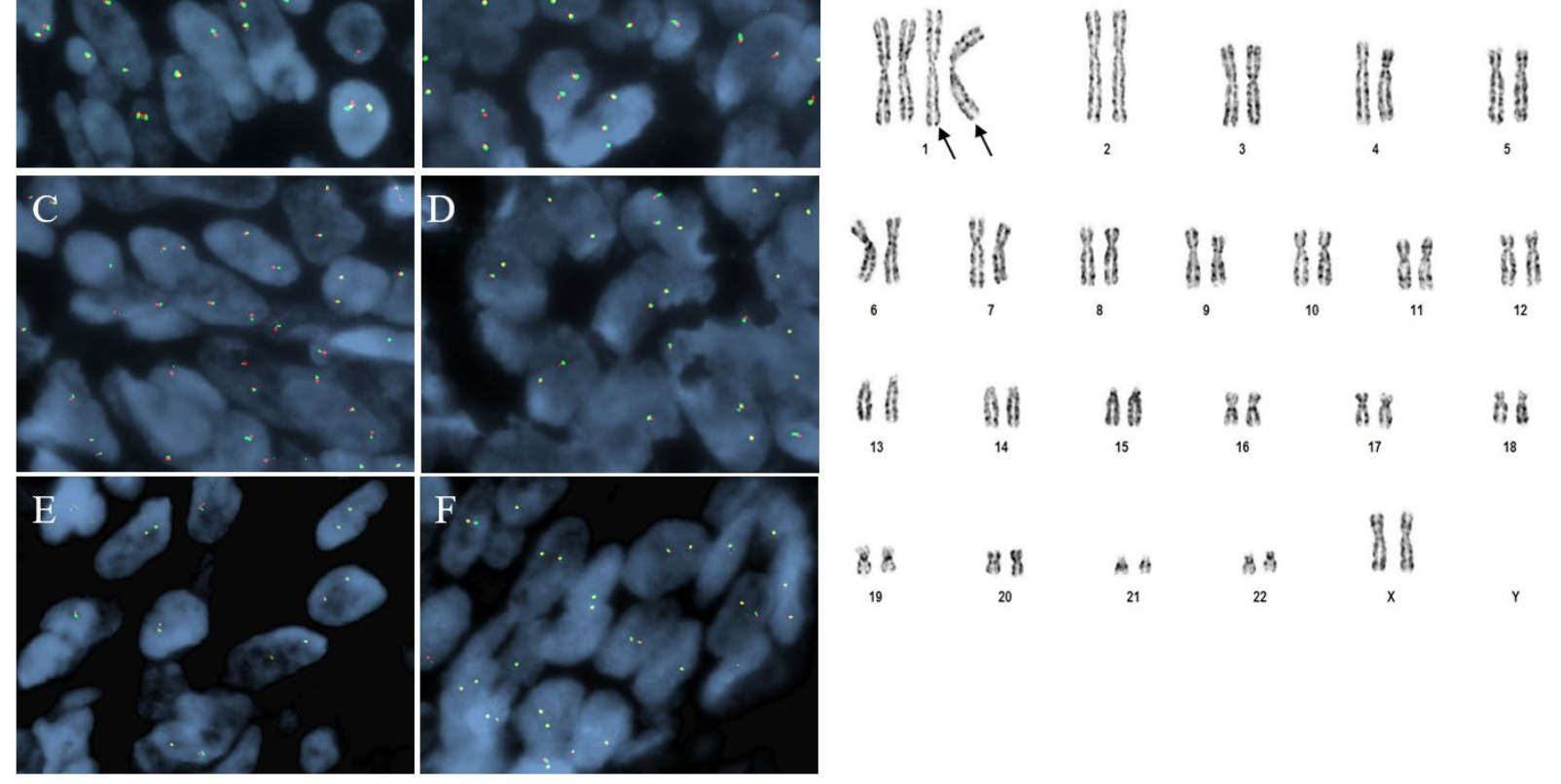

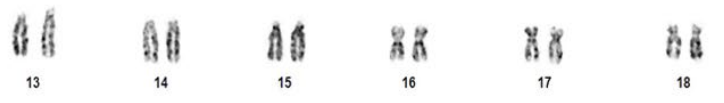

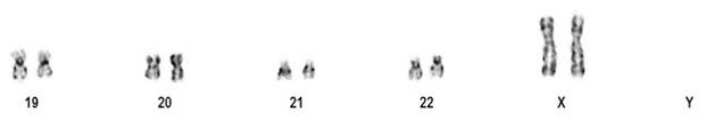

Fig 3. Cytogenetic features of endometrial stromal sarcomas. Break-apart FISH for JAZF1 (A, B), YWHAE (C, D) and PHF1 (E, F) showed normal results in the tumors from Case 1 (left) and Case 2 (right). Representative karyogram of the tumor in Case 1, demonstrating absence of any translocations classically associated with ESS (G). 


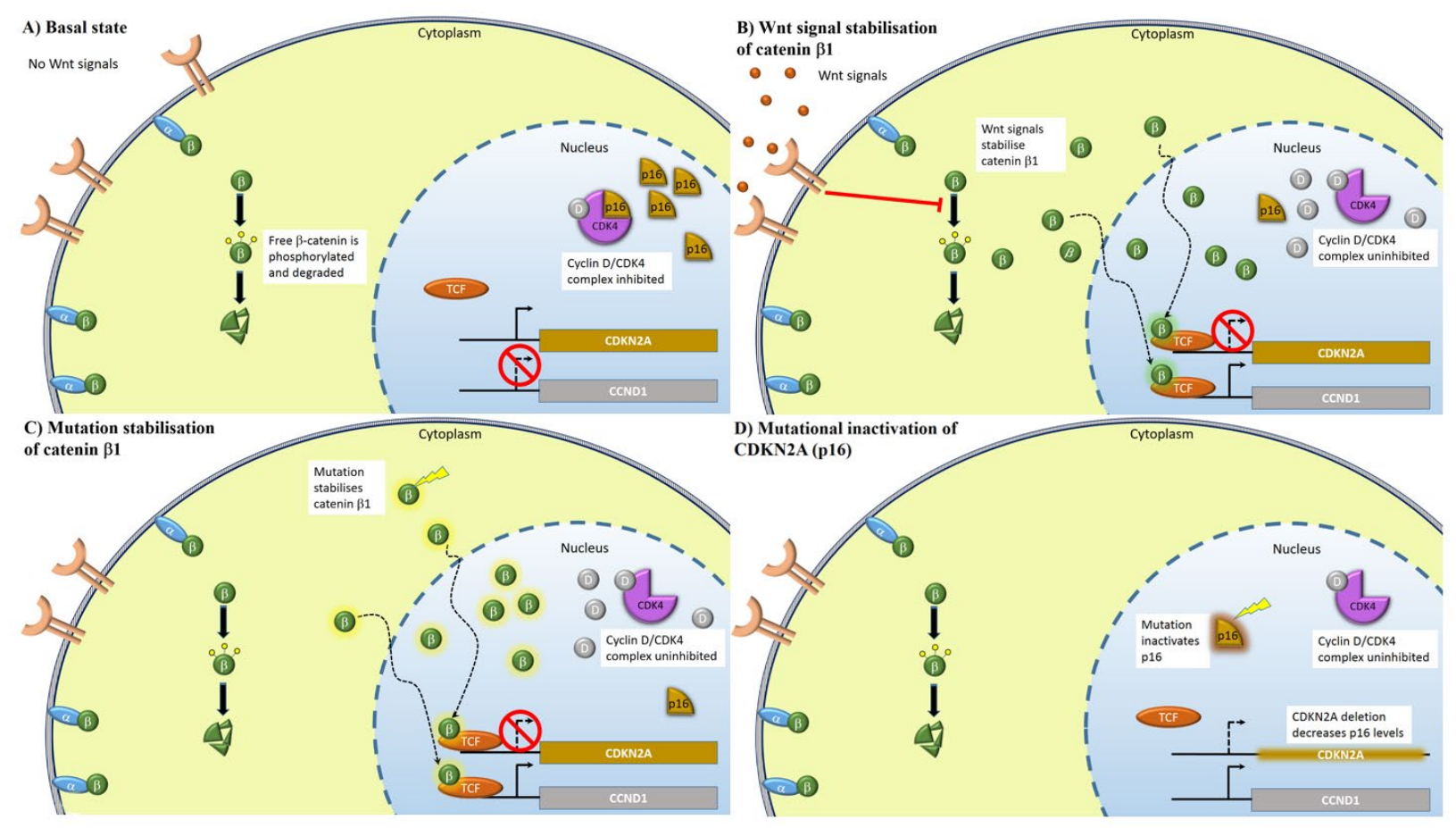

Fig 4. Potential tumorigenic mechanism of $C T N N B 1$ and $C D K N 2 A$ mutations in ESS cases. (A) In the basal state, cytoplasmic catenin $\beta 1$ is phosphorylated, ubiquitinylated, and rapidly degraded, with only the membrane-bound form detectable. (B) Stabilization occurs in the presence of (B) Wnt signals or (C) activating alterations, such as the catenin $\beta 1$ mutation in Case 1, leading to catenin $\beta 1$ accumulation, nuclear translocation, and $\mathrm{T}$ cell factor (TCF) dimerization. The dimeric transcription factor downregulates $C D K N 2 A$ (encoding p16) and upregulates $C C N D 1$ (encoding cyclin D1). (D) Decreased p16 activity may also result from loss-of-function mutations in the $C D K N 2 A$ gene, as occurred in Case 2. Ultimately, activation of catenin $\beta 1$ and/or decreased p16 results in release of cyclin D/CDK4 inhibition, passage through the G1-S checkpoint, and cell proliferation (not shown). 
SUPPLEMENTAL TABLE 1. Endometrial Stromal Sarcoma Mutation Characteristics

\begin{tabular}{|c|c|c|c|c|c|c|c|c|c|c|c|c|c|c|c|c|c|c|c|c|c|c|}
\hline $\begin{array}{l}\text { HUGO Gene } \\
\text { Symbol }\end{array}$ & HUGO Gene Name & $\begin{array}{l}\text { Cancer } \\
\text { Census } \\
\text { Gene } \\
\end{array}$ & $\begin{array}{l}\text { Role in } \\
\text { Cancer }\end{array}$ & $\begin{array}{l}\text { cDNA } \\
\text { change }\end{array}$ & $\begin{array}{c}\text { Deduced } \\
\text { Amino Acid } \\
\text { Change }\end{array}$ & $\begin{array}{c}\text { Mutation } \\
\text { Type }\end{array}$ & Effect & COSMIC ID & $\begin{array}{l}\text { Reported } \\
\text { Germline }\end{array}$ & $\begin{array}{l}\text { Reported } \\
\text { Somatic }\end{array}$ & $\begin{array}{c}\text { Recurrence } \\
\text { (counts) }\end{array}$ & $\begin{array}{c}\text { Hotspot } \\
\text { Mutation }^{1}\end{array}$ & $\begin{array}{l}\text { FATHMM }{ }^{2,3} \\
\text { Score }\end{array}$ & $\begin{array}{l}\text { FATHMM } \\
\text { Prediction }\end{array}$ & $\begin{array}{l}\mathrm{SIFT}^{2,4} \\
\text { Score }\end{array}$ & $\begin{array}{c}\text { SIFT } \\
\text { Prediction }\end{array}$ & $\begin{array}{l}\text { PolyPhen-2.5 } \\
\text { Score }\end{array}$ & $\begin{array}{l}\text { PolyPhen-2 } \\
\text { Prediction }\end{array}$ & $\begin{array}{l}\text { Tumor } \\
\text { Purity } \\
\text { (\%) }\end{array}$ & $\begin{array}{l}\text { NGS } \\
\text { VAF }^{6} \\
(\%)\end{array}$ & $\begin{array}{c}\text { Tumor } \\
\text { VAF }^{7} \\
(\%) \\
\end{array}$ & $\begin{array}{l}\text { Predicted } \\
\text { Zygosity }\end{array}$ \\
\hline CTNNB1 & catenin beta 1 & Yes & $\begin{array}{l}\text { Proto- } \\
\text { oncogene }\end{array}$ & c. $133 \mathrm{~T}>\mathrm{C}$ & p.Ser45pro & Missense & $\begin{array}{l}\text { Gain-of- } \\
\text { function }\end{array}$ & $\begin{array}{l}\text { CosM5663, } \\
\text { cosM12639, } \\
\text { CosM29398 }\end{array}$ & No & Yes & 367 & $\begin{array}{c}\text { Yes, 3rd } \\
\text { most } \\
\text { common }\end{array}$ & -7.1 & CANCER & 0 & DAMAGING & 0.988 & $\begin{array}{l}\text { PROBABLY } \\
\text { DAMAGING }\end{array}$ & 85 & 43 & 51 & Heterozygous \\
\hline CDKN2A & $\begin{array}{l}\text { cyclin dependent } \\
\text { kinase inhibitor } 2 \mathrm{~A}\end{array}$ & Yes & $\begin{array}{l}\text { Tumor } \\
\text { suppressor }\end{array}$ & $c .172 C \mathrm{~T}$ & p.Arg58Ter & Nonsense & $\begin{array}{l}\text { Loss-of- } \\
\text { function }\end{array}$ & $\begin{array}{l}\text { CosM12731, } \\
\text { CosM12473, } \\
\text { cosm53073 }\end{array}$ & No & Yes & 122 & $\begin{array}{l}\text { Yes, 2nd } \\
\text { most } \\
\text { common }\end{array}$ & N/A & $\mathrm{N} / \mathrm{A}$ & $\mathrm{N} / \mathrm{A}$ & $\mathrm{N} / \mathrm{A}$ & N/A & N/A & 85 & 79 & 93 & Hemizygous \\
\hline
\end{tabular}

Hotspot mutation = frequent mutation in given gene across all cancer types in COSMIC

${ }^{2}$ FATHMM, SIFT, \& PolyPhen-2 are variant effect prediction tools for missense mutations (not applicable to nonsense mutations; i.e., CDKN2A mutation)

${ }^{3}$ FATHMM = Functional Analysis Through Hidden Markov Models v2.3, (http://fathmm. biocompute.org.uk/, last accessed 6/10/2017)

"SIFT (http://sift.jcvi.org/, last accessed 6/10/2017)

PolyPhen-2 = Polymorphism Phenotyping v2 (http://genetics.bwh.harvard.edu/pph2/, last accessed 6/10/2017)

Tumor VAF = variant allele frequency in tumor cells (NGS VAF / Tumor Purity x 100\%) 


\section{Supplemental Text}

Discussion of Pathologic Classification of Cases

Both tumors are classified as high-grade ESS based on the current WHO classification ${ }^{1}$. The tumors display areas reminiscent of proliferative-phase endometrial stroma. In case 1, the tumor is composed of highly uniform small to intermediate sized ovoid cells with fine chromatin and occasional conspicuous nucleoli. The tumor in case 2 has somewhat larger and more pleomorphic cells with coarse chromatin. It also has foci of high-grade, round cell morphology, which is incorporated into the WHO definition of high-grade ESS. Additional features favoring high-grade over low-grade designation include advanced stage at initial presentation, very high mitotic count (60/10HPF and 50/5HPF, respectively), and ER-/PR-/cyclin D1+ immunophenotype ${ }^{1,2}$.

Neither tumor has the morphologic features of undifferentiated uterine sarcoma (UUS), other than the high mitotic rate. Profound atypia in the form of marked pleomorphism, atypical mitoses, prominent nucleoli, multinucleation, or bizarre cells was not present. The majority of tumors classified in the past as "uniform" UUS² (based on high-grade atypia and cellular uniformity) before the re-introduction of high-grade ESS in the current WHO can now be reclassified as high-grade ESS based on YWHAE, BCOR and other alterations ${ }^{3}$. There is no specific guidance on how these tumors are to be classified when molecular findings are lacking; however, some have classified them as UUS3. Whether relevant alterations were not detected because of testing limitations or whether they in fact represent a class distinct from high-grade ESS remains to be addressed. We favor classifying "uniform" UUS as high-grade ESS until data to the contrary emerges. In addition, UUS are enriched in TP53 mutations and complex karyotypes ${ }^{3}$. However, TP53 mutations were not detected in either tumor, and case 1 had a simple karyotype, findings which do not support classification of UUS.

\section{References:}

1. Kurman RJ CM, Herrington CS, Young RH, eds. WHO Classification of Tumours of Female Reproductive Organs, World Health Organization Classification of Tumours. Vol 6. Lyon, France: IARC Press; 2014.

2. Kurihara S, Oda Y, Ohishi Y, et al. Endometrial stromal sarcomas and related high-grade sarcomas: immunohistochemical and molecular genetic study of 31 cases. Am J Surg Pathol. 2008;32(8):1228-1238.

3. Cotzia P, Benayed R, Mullaney K, et al. Undifferentiated Uterine Sarcomas Represent Under-Recognized High-grade Endometrial Stromal Sarcomas. Am J Surg Pathol. 2019;43(5):662-669. 